\title{
Research on Evaluation of Efficiency of Colleges and Universities' Scientific Research in Hubei Province Based on Malmquist Index
}

\author{
Tan Zhusen \\ Wuhan University of Technology \\ Wuhan, China \\ 1137347781@qq.com
}

\begin{abstract}
To study the efficiency of scientific research and its changes in recent years in Hubei Province, the paper has complemented the existing research, first use the data envelopment analysis (DEA) analyze the efficiency of key universities in Hubei Province, then use DEA method to calculate Malmquist Index and decompose it. The results show that the overall efficiency of scientific research of the college is relatively high, but there are still existing irrational distribution of resources and other issues. Finally, this paper proposes improvements against these issues, and it will provide Government and universities with valuable reference advice.
\end{abstract}

Keywords-Data Envelopment Analysis; Efficiency; Scientific Research; Malmquist Index; Key Universities; Hubei Province

\section{INTRODUCTION}

The strategy of invigorating China through science, technology and education has increased the investment in scientific research. Nowadays, China is in economic transition period. In order to ensure sustainable economic development and lay the foundation of long-term development of the country, we should pay more attention to scientific research. However, Colleges and universities are important platform of scientific research. So it is a very important job to evaluate the efficiency of colleges and universities' scientific research and find out the cause of the waste of resources. It contributes to the full use of research resources.

Hubei is a province with many colleges and universities. Up to 2014, it has 32 provincial Universities, including seven "211 Project" universities and two "985 Project" universities. These universities' research work played an important role in Hubei's economic growth. According to statistics, Hubei Province has invested 68 million yuan to 53 universities as research funding in 2013. However, whether the government has done reasonable allocation of these resources, whether the university has made full and efficient use of research resources remains to be seen. In this paper, DEA method is used to calculate Malmquist index of nine key universities' research efficiency in Hubei province. The result shows that some universities have unreasonable investment and allocation of research resources, according to the result, the paper has come out with proposed improvements for colleges and universities. It will help universities improve research resource utilization while providing valuable suggestions to the government to optimize the allocation of research resources.

The way to study the efficiency of scientific research varies a lot, such as Analytic Hierarchy Process, BSC and comprehensive evaluation with common multiple indicators. However, these methods have significant deficiencies. For example, AHP is quite subjective with a large number of qualitative indicators, and it also does not contribute to decision-making. BSC requires a lot of indicators, and it does not apply to strategy development, in addition, to determine and assign the weights to indicators are more difficult, resulting in a lot of costs during implementation process.

To overcome the shortcomings mentioned above, this paper combines DEA with Malmquist index

DEA has unique advantages in performance evaluation method. As we know, multiple-input / multiple-output is the main characteristic of university research system. However, the most prominent advantage of the DEA is to evaluate the effectiveness of the multi-input / multipleoutput system. This is mainly because the DEA does not require pre-determined weight of index rather regard the weight of the input and output as variables. In this way, subjective factors in determining the weights can be avoided. Additionally, DEA method need not determine the relationship between the input and output variables.

Foreign scholars have used DEA method evaluate the performance of the university successfully. Such as Agrell and Steuer (2000), they used DEA study the performance of in the university faculties in American. Their research includes five evaluation indexes, involving 30 decisionmaking units, and the results showed that DEA is a feasible method in evaluating Universities' performance [2]. Another instance, Worthington,A.C(2008) use Malmquist Index study the varies of teaching efficiency of Australian universities between 1998 to 2003, the results show that the teaching efficiency of Australian university increased by $3.3 \%$ per year during this period on average[3]. K Chen and IS Chen (2011) using data envelopment analysis method to study the teaching performance of Taiwan colleges and universities, the results show that $73 \%$ of Taiwan's colleges and universities are in a relatively inactive state, the authors also have put forward measures to integrate innovation and reduce costs [4]. These studies are a model of DEA application in terms of performance evaluation research. These previous studies provide a reference example to this paper. 
There have been a lot of Chinese scholars evaluated efficiency of scientific research in colleges and universities with DEA method, representatives are Guangming Hou,Shuicheng Tian [5]. These scholars confirmed the DEA method is feasible and have certain advantages in evaluating the performance of university. However, there are still many defects, such as Lu Genshu (2006) and (2013). Lu Genshu use DEA method carried out research efficiency of 54 key colleges and universities, similarly, Yin Weihua does it with bootstrap-DEA method. But these universities are not in the same area, so the result can not represent the research efficiency level of specific area [6-7]. Sun Shimin (2007) using the DEA method evaluate the research efficiency of certain provinces, after a year, Qi Yong (2008) also use DEA method to evaluate the efficiency of scientific research of 21 colleges and universities in Jiangsu Province, but they used only a sectional data in one year, it does not reflect the trends of efficiency of scientific research in universities within certain period of time [8-9]. Liao Wenqiu (2011) use Malmquist index analyze the universities' efficiency of humanities and social sciences research in Jiangsu province, but this article only used Malmquist index rather than combine DEA model with it, and the data is out of date. So it can not represent current efficiency improvement level [10].

Stimulated by the foregoing points, the objective of this paper is to propose new methodologies to rectify shortcomings of previous research. Combining Malmquist Index and DEA, this paper studied the research efficiency of nine major universities in Hubei province during 2008 and 2013. By using the basic DEA model, this paper analyzed investment redundancy and output insufficiency in research quantitatively, based on panel data, the development trend of university research efficiency has been studied. Additionally, using DEA method to calculate the Malmquist index and decompose it, we can find the root of the problem from the aspect of technology and efficiency, and then proposed improvements to solve these problems. Finally, the paper speculated that the general colleges and universities have the same situation as the nine representative one. It provides theoretical support to the college in enhancing the efficiency of scientific research, thus contributes to the relevant departments of making decisions.

\section{MALMQUIST INDEX}

The Malmquist index was first proposed by Malmquist (1953). Many people use DEA method to calculate the Malmquist index. In this study, the adjacent reference Malmquist index was used. From the period $t$ to $t+1$, Malmquist index was expressed as [11]:

$$
M_{a c}\left(x^{t+1}, y^{t+1}, x^{t}, y^{t}\right)=\sqrt{\frac{E^{t}\left(x^{t+1}, y^{t+1}\right)}{E^{t}\left(x^{t}, y^{t}\right)} \frac{E^{t+1}\left(x^{t+1}, y^{t+1}\right)}{E^{t+1}\left(x^{t}, y^{t}\right)}}
$$

E indicates the efficiency value, the superscript is the period of reference set, and indicate the input and output vectors respectively in the corresponding of each period, and indicate the technical efficiency value respectively in the period of $\mathrm{T}$ and $\mathrm{T}+1$,Färe(1992) defined their ratio EC as the technical efficiency change of the two periods:
$E C=\frac{E^{t+1}\left(x^{t+1}, y^{t+1}\right)}{E^{t}\left(x^{t}, y^{t}\right)}$

Use to show the change of the leading edge in the period between $t$ and $t+1$ :

$$
T C_{a c}=\sqrt{\frac{E^{t}\left(x^{t}, y^{t}\right)}{E^{t+1}\left(x^{t}, y^{t}\right)} \frac{E^{t}\left(x^{t+1}, y^{t+1}\right)}{E^{t+1}\left(x^{t+1}, y^{t+1}\right)}}
$$

Then we can get:

$$
\begin{aligned}
& M_{a c}\left(x^{t+1}, y^{t+1}, x^{t}, y^{t}\right)=\sqrt{\frac{E^{t}\left(x^{t+1}, y^{t+1}\right)}{E^{t}\left(x^{t}, y^{t}\right)} \frac{E^{t+1}\left(x^{t+1}, y^{t+1}\right)}{E^{t+1}\left(x^{t}, y^{t}\right)}} \\
& =\sqrt{\frac{E^{t}\left(x^{t}, y^{t}\right)}{E^{t+1}\left(x^{t}, y^{t}\right)} \frac{E^{t}\left(x^{t+1}, y^{t+1}\right)}{E^{t+1}\left(x^{t+1}, y^{t+1}\right)}} \frac{E^{t+1}\left(x^{t+1}, y^{t+1}\right)}{E^{t}\left(x^{t}, y^{t}\right)}
\end{aligned}
$$

That means, in this way, the Malmquist index is divided into two parts: the efficiency change and technological change. Through this decomposition, we can find the real cause of the low MI value, and then put forward the improvement measures.

Stimulated by the foregoing points, the objective of this paper is to propose new methodologies to rectify shortcomings of previous research. Combining Malmquist Index and DEA, this paper studied the research efficiency of nine major universities in Hubei province during 2008 and 2013. By using the basic DEA model, this paper analyzed investment redundancy and output insufficiency in research quantitatively, based on panel data, the development trend of university research efficiency has been studied. Additionally, using DEA method to calculate the Malmquist index and decompose it, we can find the root of the problem from the aspect of technology and efficiency, and then proposed improvements to solve these problems. Finally, the paper speculated that the general colleges and universities have the same situation as the nine representative one. It provides theoretical support to the college in enhancing the efficiency of scientific research, thus contributes to the relevant departments of making decisions.

\section{INDEX SYSTEM AND DATA SOURCES}

Universities' scientific research system is a complex system with multiple inputs and multiple outputs. How to establish the evaluation index concerns the accuracy of the evaluation results, the establishment of the index system should follow the following principles:

- Streamlining the number of indicators.

- The indicators should be independent.

- The indicators should be typical

- Considering the operability of the index and the ease of data.

On the basis of previous studies, this study comprehensively considers the factors of human, financial and material resources and finally select the number of teaching staff and scientific researchers, government funds, enterprises and institutions' entrusting as input indexes, the total number of projects, scientific and technological achievements as output indexes. This paper concerns 9 
key universities in Hubei province as decision-making units and uses data from the year 2008 to 2013. The data of this study were compiled by the Ministry of education of the People's Republic of China.

The template is used to format your paper and style the text. All margins, column widths, line spaces, and text fonts are prescribed; please do not alter them. You may note peculiarities. For example, the head margin in this template measures proportionately more than is customary. This measurement and others are deliberate, using specifications that anticipate your paper as one part of the entire proceedings, and not as an independent document. Please do not revise any of the current designations.

\section{RESULT}

In order to investigate the efficiency variation of decision-making units from 2008 to 2013, Total Factor Productivity (TFP) Malmquist is used to analyze the data. The results show that how much contributes the technical progress or technical efficiency does to the variation of TFP. The Malmquist index is more than 1 means the productivity has been improved, and the Malmquist is less than 1 means the productivity has declined. The Malmquist index is 1 means the productivity is remaining unchanged. The Malmquist index of the decision-making units is shown in TABLE I:

TABLE I. THE MALMQUIST INDEX OF THE DECISION-MAKING UNITS

\begin{tabular}{cccccc}
\hline $\begin{array}{c}\text { DM } \\
\text { U }\end{array}$ & $\begin{array}{c}\mathbf{2 0 0 8}- \\
\mathbf{2 0 0 9}\end{array}$ & $\begin{array}{c}\mathbf{2 0 0 9 -} \\
\mathbf{2 0 1 0}\end{array}$ & $\begin{array}{c}\mathbf{2 0 1 0 -} \\
\mathbf{2 0 1 1}\end{array}$ & $\begin{array}{c}\mathbf{2 0 1 1 -} \\
\mathbf{2 0 1 2}\end{array}$ & $\begin{array}{c}\mathbf{2 0 1 2 -} \\
\mathbf{2 0 1 3}\end{array}$ \\
\hline A & 0.786 & 1.075 & 0.876 & 1.057 & 0.933 \\
B & 1.306 & 0.888 & 0.886 & 1.161 & 0.833 \\
C & 0.966 & 0.912 & 1.037 & 1.134 & 1.086 \\
D & 0.806 & 0.967 & 0.951 & 0.898 & 1.35 \\
E & 0.52 & 1.91 & 0.332 & 1.168 & 0.858 \\
F & 0.859 & 1.058 & 0.744 & 0.796 & 5.062 \\
G & 0.767 & 0.763 & 0.993 & 1.018 & 1.032 \\
H & 0.776 & 0.699 & 1.35 & 0.834 & 1.208 \\
I & 0.353 & 0.857 & 1.225 & 0.97 & 3.032 \\
\hline
\end{tabular}

As can be seen from TABLE I, only the Malmquist index of B (Huazhong University of Science and Technology) is more than 1in 2008-2009. The number of decision-making units which has a Malmquist index greater than 1 increased to more than 3 from 2009 to 2011, and increased to 6 during 2012 to 2013. The change reflects that the trend of the 9 universities' scientific research efficiency is increasing. In addition, from the specific data point of view, the first few years there has been lower value such as 0.353 and 0.52 , after a few years there has been a relatively large value such as 3.032,5.062 and so on, the magnitude of the increase in productivity is bigger and bigger.

Färe R (1994) divided the technical efficiency change (effch) into pure technical efficiency change (Pech) and scale efficiency change (sech) [12], i.e.

Effch* techch $=$ pech* sech Tfpch $=*$ techch $(6)$

The geometric mean of the total factor productivity of each period is decomposed, and the results of TABLE II can be obtained.
TABLE II. THE GEOMETRIC MEAN OF THE TOTAL FACTOR PRODUCTIVITY

\begin{tabular}{cccccc}
\hline year & effch & techch & pech & sech & tfpch \\
\hline $\mathbf{2 0 0 8 - 2 0 0 9}$ & 0.998 & 0.751 & 0.957 & 1.043 & 0.75 \\
$\mathbf{2 0 0 9 - 2 0 1 0}$ & 1.062 & 0.916 & 1.046 & 1.015 & 0.972 \\
$\mathbf{2 0 1 0 - 2 0 1 1}$ & 0.967 & 0.908 & 1.018 & 0.95 & 0.878 \\
$\mathbf{2 0 1 1 - 2 0 1 2}$ & 0.996 & 0.999 & 0.994 & 1.002 & 0.995 \\
$\mathbf{2 0 1 2 - 2 0 1 3}$ & 0.963 & 1.438 & 1.006 & 0.957 & 1.385 \\
mean & 0.997 & 0.979 & 1.004 & 0.993 & 0.975 \\
\hline
\end{tabular}

Table 4 reflects the overall efficiency of the research in 9 colleges and universities between 2008 and 2013. From the perspective of total factor productivity (tfpch), we can see that the total factor productivity is increased from 0.75 to 1.385 , and the scale efficiency and pure technical efficiency are more than 1 , which indicates that the improvement of total factor productivity is mainly from pure technical efficiency and scale efficiency. It can be seen from the results that the technical efficiency is more than 1only between 2012 and 2013, up to 1.438 . According to the formula (6), low efficiency is the main reason of the low total factor productivity, the trend in table 5 can be reflected by Fig.1. The trend of the change of technical efficiency and total factor productivity curve is very similar, and the two exerted a smooth increasing during past six years. It says that colleges and universities in Hubei consider improving the efficiency of technology as the main battlefield, in addition, pure technical efficiency and scale are the breakthrough point to improve efficiency, because the trend of efficiency curve, pure technical efficiency curve and scale change are consistent, all of them are fluctuate around 1.

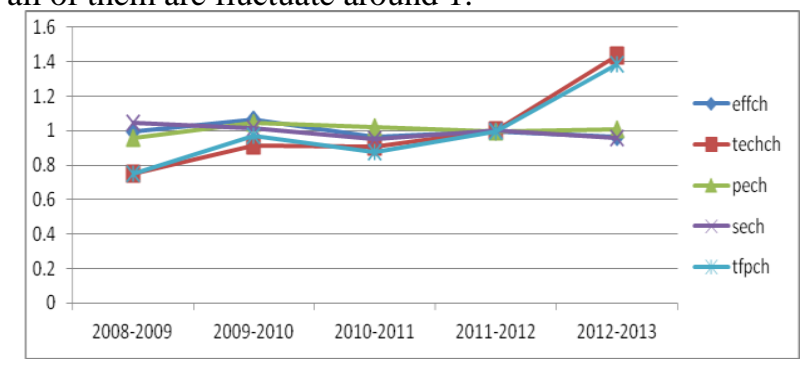

Figure 1. The Trend of TFP

\section{CONCLUSIONS AND SUGGESTIONS}

Through the analysis above, we can find that most of decision-making units are in the state of relative effectiveness in scientific research. From 2008 to 2013, total factor productivity overall showed a rising trend, but there still exist a lot of problems, and has a great room for improvement. The selected 9 key universities in Hubei Province are representative in terms of efficiency of scientific research, so we can infer from these colleges and universities that other colleges and universities also exist the same problems, universities can take measures for improvement and further optimizing the scientific resources utilization. 


\section{A. Irrational Allocation of Scientific Research Resources} Resulting in the Poor Utilization of Resources .

"985" or "211" University's human and financial resources are relatively abundant, but they accounted for a large proportion in the non-efficiency decision-making units. Many colleges and universities even has remaining resources, so the allocation of resources is unreasonable. To make the scientific research efficiency is relatively effective, it is appropriate to adjust the proportion of scientific research resources, the ratio can be adjusted according to the model of the evaluation results.

B. The Subjective Initiative of the University is Low, and the Transformation Rate of Scientific Research

Results Need to be Improved.

The low subjective initiative performances are at low scientific and technological achievements and lesser research project. Taking the results in 2012 as an example, remaining the input unchanged,. The total number of $\mathrm{A}$ should be increased by 436 units and the total number of $F$ is increased by 66 units in order to make the decision unit DEA effective. Similarly, the number of scientific and technological achievements is not ideal. The transformation rate of scientific and technological achievements is reflected in the lack of the transfer of the output technology, the improvement of the decisionmaking unit A reached 3929 units, accounting for $70 \%$ of the original value. The decision unit F's improved value is up to 158 units, reached $38 \%$ of the original value. This shows that universities should fully exert their subjective initiative to make full use of scientific research resources. On the other hand, they shoulds reform the innovation mode and promote the transformation and application of scientific research results and improve the efficiency of scientific research. The government should introduce the relevant incentive policies and mobilize the enthusiasm of scientific research in Colleges and universities and promote the transformation and application of scientific research results through the development of docking projects.

\section{The Organization Management and the Scientific Research System has a Large Improvement Space.}

Although the number of the decision-making units which total factor productivity increased gradually increased from 2008 to 2013, but the two "985" Engineering Colleges and universities-Huazhong University of Science and Technology and Wuhan University did not act as a leader in the six years. The relevant universities should integrate resources, and take measures to strive for the growth of Malmquist index. The result of Malmquist index decomposition shows that the main reason of low efficiency is the low efficiency of total factor productivity. Hubei university should take advantage of the talents and introduce advanced technology to improve the technical efficiency. On the other hand, the pure technical efficiency is an important breakthrough, but the pure technical efficiency of Hubei University's growth rate is not so ideal, the relevant universities should continue to improve the organization structure and improve the scientific research management system. As to Hubei Province, the government should strengthen the supervision and government regulation to ensure the stable growth of pure technical efficiency and thus promote the growth of Malmquist index.

\section{REFERENCES}

[1] DU DONG. PANG Qin-hua. Modern comprehensive evalution method and case[M]. Bei Jin:Tsinghua University Press,2008.

[2] P.J. Agrell and R.E. Steuer. ACADEA-A Decision Support System for Faculty Performance Reviews[J]. Journal of Multi-Critera Decision Analysis,20009(5):191-204

[3] Worthington,A.C \&Lee,B.L. Efficiency ,technology and productivity change in Australia universities 19982003[J].Economics of Education Review,2008,27(3):285-298.

[4] JK Chen. IS Chen. Inno-Qual efficiency of higher education:Empirical testing using data envelopment analysis[J].Expert Systems with Applications,2011,(3):1823-1834.

[5] JIANG Tong-tong.Research summary of colleges and universities performance evaluation method[J],Jiangsu Higher Education,2011(6) : 50-55.

[6] YING Wei-hua,YUAN WEI. The research on scientific research efficiency of Subordinate Universities of Minisitory of Education based on Bootstrap-DEA[J]. Statitics \& Information Forum,2013,28 (6) : 21-69.

[7] LU Geng-shu,LIU LEI,SUN Jin-chun,GU Li-na, Study on the evaluation of scientific reserach efficiency of universities derectly under the ministry of education $[\mathrm{J}]$. Journal of Xi'an Jiaotong University, 2005, 25(2):75-79.

[8] SUN Shi-min,XIANG Hua-lu,LAN Bo.The efficiency analysis on output and input science research in regional universities on basis of dea $[J]$. Science And Science Management,2007(7) : 18-21.

[9] QI Yong,LI Qian-mu,WANG Yan. The university scientific research perfofmance appraisal method based on DEA[J]. Science and Science Management, 2008 (12):178-186.

[10] LIAO Wen-qiu,LIANG ling,SONG Ma-lin. Analysis of efficiency of colleges and universities' scientific research based on malmquist index[J].System Engineering, 2011, 29(7): 64-69.

[11] CHENG Gang.Data envelopment analysis method and Maxdea [M].Beijing, Intellectual Property Right Press, 2014.

[12] Färe R,Grosskopf S,Norris M,Zhang Z. Productivity Growth Technical Progress and Efficiency Change in Industrial Countries [J].American Economic Review,1994(84):66-83. 